\title{
Ruínas futuristas do Cinema Brasileiro Contemporâneo
}

\author{
Futuristic ruins of Contemporary Brazilian Cinema
}

ANA CAROLINE DE ALMEIDA

Doutora no programa de pósgraduação em Comunicação na UFPE, com pesquisa centrada no cinema contemporâneo brasileiro. Faz parte da equipe curatorial do Festival Olhar de Cinema/Curitiba. https://orcid.org/0000-00023191-6391

caroline.almeida@gmail.com

\section{RESUMO}

Parte do cinema brasileiro pensado e elaborado nos anos 2010 produziu gestos sintomáticos da corrida desenvolvimentista e imobiliária em grandes cidades brasileiras a partir de leituras temporais não-lineares. A partir de uma constelação de imagens acionadas por um grupo de cinco filmes, este artigo busca aproximar sequências a partir de dois conceitos temporais distintos: o tempo espiralar em rituais do Congado (MARTINS, 2002) e o tempo Exu (SODRÉ, 2017). Com eles, é possível percebemos parte do cinema brasileiro revelando, em suas cidades, a estrutura fóssil em projetos de futuro.

Palavras-chave: cinema brasileiro; ruínas; temporalidade

\section{ABSTRACT}

Part of Brazilian cinema envisioned and produced in the 2010s showed us symptomatic gestures of a development and real estate race in big Brazilian cities from a non-linear temporal perspective. Based on a constellation of images triggered by a group of five films, this article seeks to approximate sequences based on two different temporal concepts: the spiral time in the "Congado" rituals (MARTINS, 2002) and the "Exu" time (SODRE, 2017). With them, it is possible to perceive that part of Brazilian cinema is revealing, through the cities depicted, the fossil structure of future projects.

Keywords: Brazilian cinema; ruins; temporality 

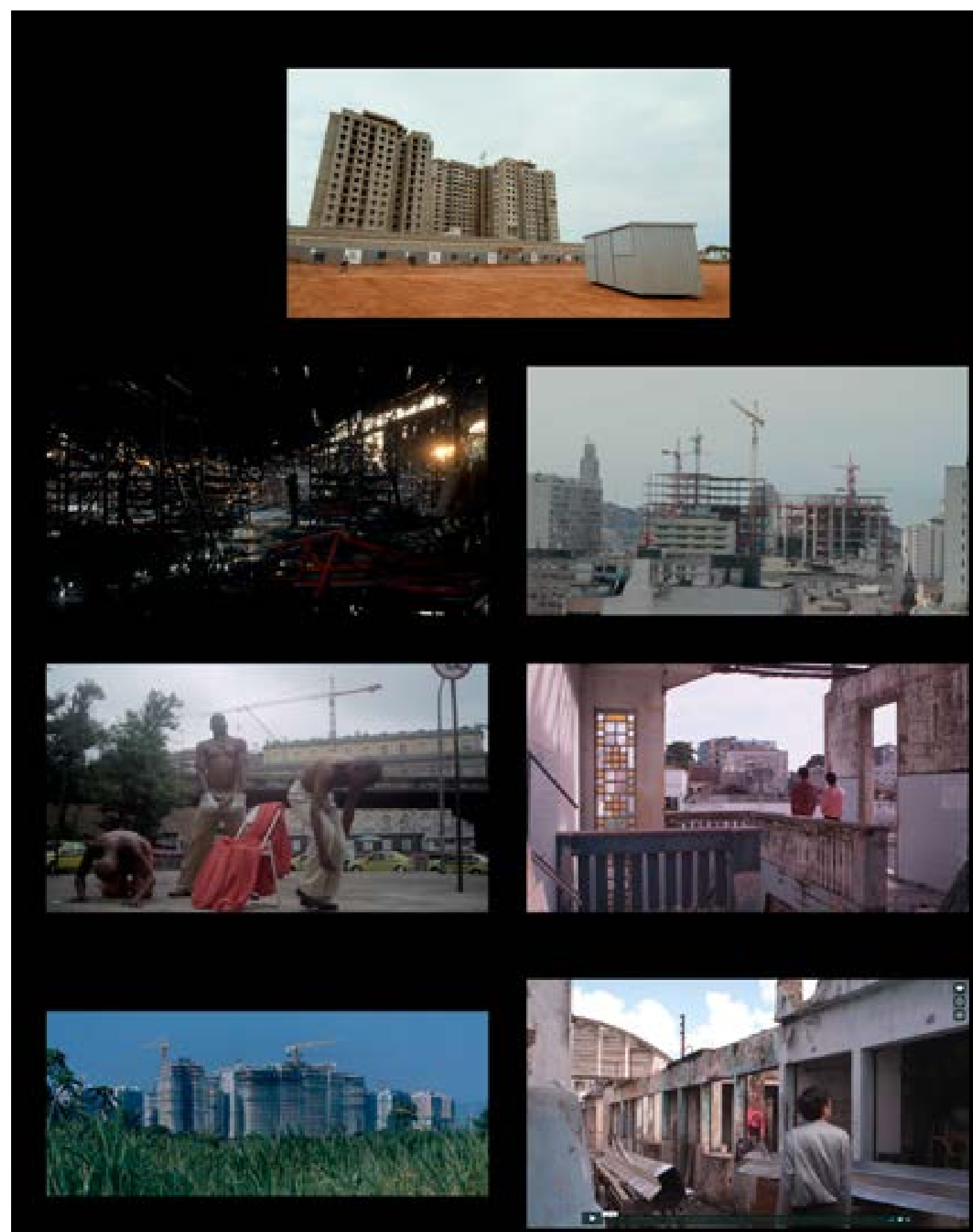

FIGURA 1: Print de tela

"Aqui tudo parece que é ainda construção e já é ruina"

Caetano Veloso 
O cinema autoral brasileiro dos anos 2010 foi rico e prolífico em sua capacidade de fazer vibrar, dentro de diferentes regimes narrativos, algumas angústias e desejos em comum no que diz respeito à experiência sensível de habitar grandes centros urbanos e, consequentemente, seus modernos projetos de existência. Durante esse período, o cruzamento de dois fatores fez o conceito de cidade adquirir uma centralidade no cinema nacional: primeiro, a rápida mudança nas paisagens dos grandes centros urbanos brasileiros, em função de fatores como intensa especulação imobiliária e gentrificação dos espaços (ambas situações movidas muitas vezes por grandes projetos urbanos). Simultaneamente, houve também uma crescente sensibilidade do pensamento subalterno e periférico sobre a herança histórica brasileira que separa classes e cores a partir de uma camuflada política que autoriza alguns e proíbe outros de ocupar determinados espaços.

Parte desse cinema produziu registros sintomáticos da corrida desenvolvimentista e imobiliária a partir de leituras temporais sobre os espaços filmados. Leia-se: quando deu a ver fenômenos concretos como o direito ou não direito a ocupar cidade; perturbações psicogeográficas de se viver em grandes centros urbanos ou viver em cidades cindidas pelo racismo, classismo e pela perseguição a qualquer corpo dissidente, fez isso muitas vezes acionando desvios na temporalidade. Fala-se aqui de filmes que ora elaboram um tempo suspenso, onde o tempo em si parece não passar; ora trazem sequências que revelam a espiralidade do tempo, o capturando em seus processos cíclicos; e ora torcem as relações entre passado, presente e futuro a partir de narrativas distópicas: "A encenação de presentes incertos e a especulação de 'futuros' têm se tornado veículo, no cinema brasileiro recente, para figurações distópicas em que a experiência em grandes cidades brasileiras recebe tons sombrios, por vezes apocalípticos." (MESQUITA, 2017, p. 89).

A proposta é, dessa forma, repensar esses gestos sintomáticos a partir de epistemologias que não comportam a noção de tempo enquanto sucessão de eventos ou mesmo como duração, mas sim como um fenômeno criado por acontecimentos que geram movimentos cíclicos, que se abrem para trás e para frente. Em um primeiro momento, o artigo caminha pelos gestos em si, pelas expressões e formas na composição de cada uma das sequências analisadas, para somente depois criar articulações entre as intensidades presentes em cada uma das cenas e duas noções temporais específicas: o Tempo Exu, tal como descrito por Muniz Sodré, e o Tempo Espiralar, conceito mobilizado por Leda Maria Martins.

Quanto às imagens cinematográficas, a intenção é partir de Branco sai preto fica (2015), de Adirley Queirós, mais especificamente de duas sequências desse filme, e usá-las como campos vibracionais que atraem outras sequências de outros filmes. Todas elas orbitam ao redor de uma ideia de que estamos em um território de ruínas futuristas (Fig. 1), ou seja, de projetos de cidade que se vendem como novos a despeito de atualizarem ciclicamente práticas coloniais de divisão dos espaços. Essas imagens, juntas, criam uma psicogeografia, uma sensação por dentro da 
qual o artigo pretende caminhar. Chegamos então a uma cidade estacionada e condenada a viver para sempre em um futuro que já chegou, já foi embora e já voltou no mesmo galope. Edifícios desabitados, terrenos tomados por mato, tratores estacionados, vigas expostas: os fósseis do progresso com os quais se esbarra nas ruas são, na verdade, testemunhos de acontecimentos porvir. Mas diferente de todas as outras cidades que conhecemos, esta que aqui se anuncia a partir de algumas imagens do cinema brasileiro contemporâneo e como elas mantém uma relação espaço-tempo que não corresponde àquela do mundo-tal-qual-o-conhecemos.

As sequências que se avizinham neste artigo têm palpitações em comum nas formas de enquadramento, no pensamento sobre como os corpos ocupam a imagem, na reelaboração de eventos traumáticos e na superfície visível concentrada de esvaziamento. Mas sobretudo, elas latejam a sensação de que algo, no caminho de um discurso racional que se acostumou a elaborar o futuro como uma evolução do passado, foi abandonado. E que será preciso reconfigurar os sentidos para aprender a viver dentro desse abandono.

\section{O TEMPO QUE SE VIAJA}

O segundo longa-metragem de Adirley Queirós aciona ferramentas da ficção científica, tais como o novum ficcional (objetos e engenhocas nunca antes vistos), para levar um viajante do tempo, Dimas Cravalança, ao passado? presente? futuro? de Ceilândia, cidade-satélite do Distrito Federal, e assim tentar fazer justiça em nome de todas as pessoas periféricas que sofreram os crimes perpetrados pelo Estado brasileiro. Em Branco sai preto fica, são pelos códigos da viagem no tempo que se consegue lidar com uma região onde já se instala um apartheid institucionalizado pelo Estado e onde corpos negros, aqui representados por dois homens, terminam por ser mutilados para que seus direitos de circulação e ocupação da cidade sejam negados. Nessa cidade, a população vive sob constante vigilância e toques de recolher. Marquim (Marquim do Tropa) e Shokito (Claudio Irinaeus), o primeiro paraplégico e o segundo com uma das pernas amputada, maquinam uma explosão sonora contra o Estado assassino enquanto Dimas (Dilmar Durães), enviado de um futuro não menos trágico para o país, tenta reverter a ordem-e-progresso da História. 


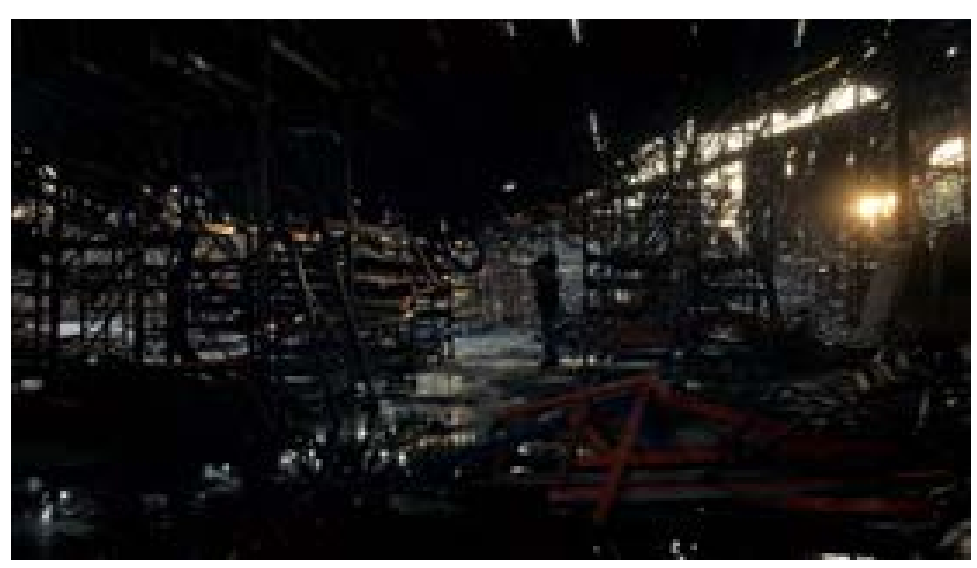

FIGURA 2: Print de tela

Quando sobe a música final de Branco sai preto fica, começam a surgir desenhos que representam o apocalipse de Brasília. Neles, o que se vê é a capital federal e seus famosos monumentos do poder sendo destruídos. O pânico está instalado nas imagens enquanto o som alto de MC Dodô cantando "Bomba explode na cabeça" toma a sala de cinema. Mas eis que a música para repentinamente. Surge então a imagem do personagem Dimas Cravalança (Dilmar Durães) em meio àquilo que, supomos, sejam os escombros de Brasília. As ferragens que sobraram no pós-apocalipse (Fig. 2). É um plano fixo, silencioso, contemplativo, que funciona como o ponto final da história. A luz do dia mal consegue iluminar a imagem, dada a quantidade de entulhos que se somam ao redor de Dimas, o agente enviado do futuro para salvar o Brasil de si mesmo. A própria figura de Dimas parece também se confundir, de forma camuflada, ao ferro velho. Esses segundos de pós-apocalipse em que se vê o personagem sozinho em um território implodido é uma inflexão no desfecho catártico do filme, uma pausa curta antes de a música retornar e os créditos subirem, mas importante o suficiente para que se estabeleça uma dúvida: será que esse é realmente o fim do mundo ou o fim do mundo já estava entre nós? Afinal, esse cenário de escombros e ferros velhos já havia sido previamente apresentado no filme. Em que tempo está essa cena? No futuro? No passado? Ou em algum intervalo fora da cronologia? 


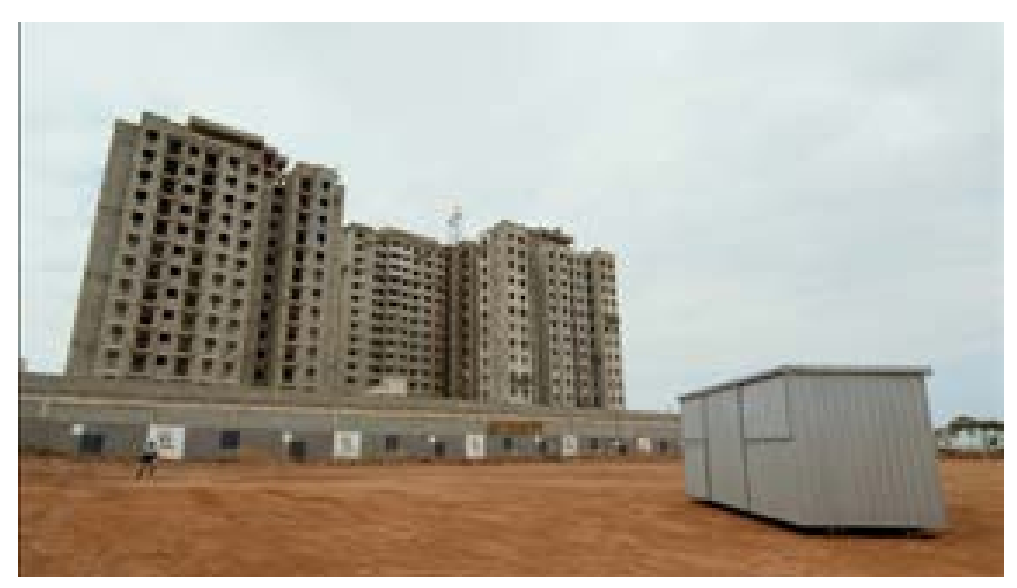

FIGURA 3: Print de tela

Quando a nave espacial de Dimas Cravalança pousa na Terra, ela estaciona no meio de um terreno baldio (Fig. 3). Atrás desse terreno, mais um edifício cuja construção parece ter sido abandonada. Cobrindo tudo isso, um céu chapado, nem chuva, nem sol, um céu sem vida, sem drama. A grande angular amplifica a sensação de esvaziamento. Uma sirene dispara, algum alerta está sendo emitido. Dimas, corpo ínfimo dentro da imagem, cruza o quadro correndo e entra em sua nave do futuro. Essa máquina do tempo é, na verdade, um contêiner, desses que atravessam oceanos em navios de carga levando mercadorias fabricadas com mão de obra barata. A imagem desse contêiner-nave diante de um grande edifício inacabado e abandonado é uma sofisticada elaboração de mise-en-scène que usa dos artifícios da invenção na precariedade para fazer vibrar um estado de falência não apenas de um projeto de cidade, mas de uma metástase na própria estrutura do Capital cujos sintomas aparecem primeiro na epiderme dos centros urbanos. Trata-se de uma imagem minimalista nos objetos que a adornam. Prédio, "nave", homem, céu chapado e um vasto chão de terra batida. Uma imagem que, portanto, transmite sensações imediatas de ausência e, sobretudo, impotência, tão pequeno é esse homem dentro de um espaço que o parece esmagar. 
A materialidade do vazio e as estruturas de ruína que saltam de ambas essas sequências me levam a pensar sobre como outros filmes brasileiros terminaram por ecoar energias semelhantes. São filmes que, apesar de terem sido realizados em períodos próximos, surgiram com propostas formais bastante distintas das que Adirley Queirós faz uso em Branco sai preto fica, e não apenas trazem no centro de suas narrativas a angústia de se habitar em projetos falidos de cidades, mas sobretudo revelam a partir de algumas composições a possibilidade de se pensar o tempo não mais a partir de um eixo cronológico.

\section{O TEMPO QUE SE SUSPENDE}

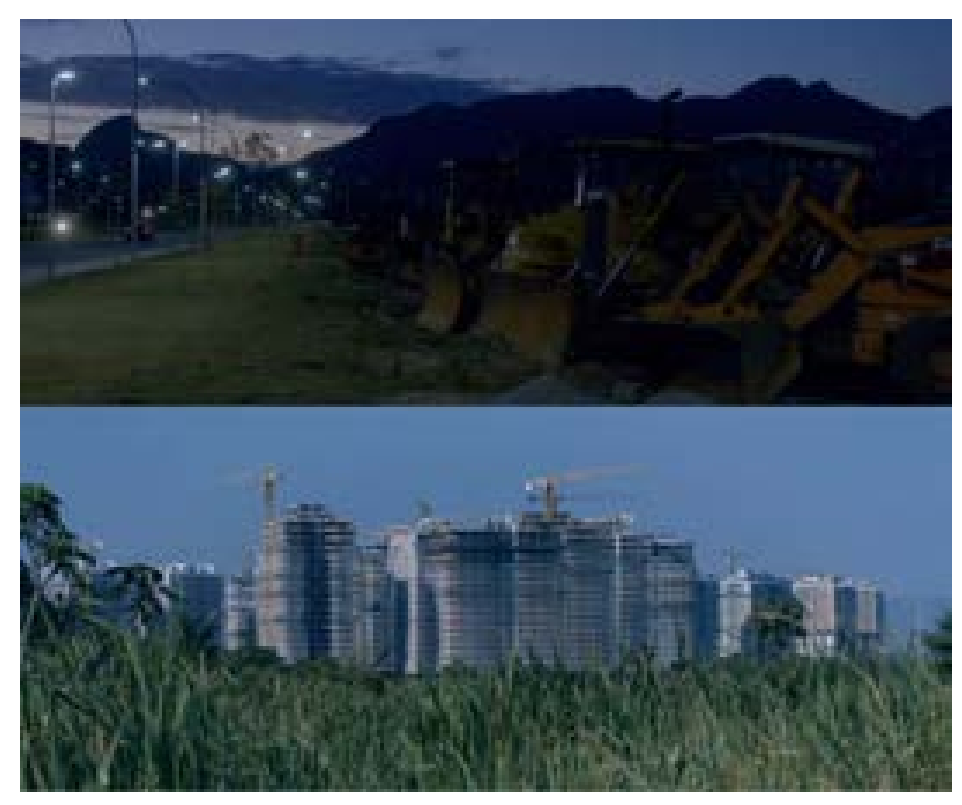

FIGURA 4: Print de tela

Construções abandonadas que emolduram espaços esvaziados de vida são uma centralidade dramática em Mate-me por favor (2015), de Anita Rocha da Silveira. Na Fig. 4, no enquadramento de cima, existe uma linha invisível que corta verticalmente a imagem em duas. Do lado esquerdo, o fundo infinito de uma avenida que parece se dirigir rumo às montanhas. Do lado direito, uma fila de tratores parece estar de prontidão à espera de um chamado que não vem. No outro plano, a composição se monta com três naturezas distintas: o mato em primeiro plano que cresce 
solto em um terreno desabitado, os prédios em construção ao fundo envelopados por lonas e guindastes e, finalmente, o céu azul que cobre a parte superior da imagem.

A cidade filmada por Mate-me por favor é uma que decidiu, voluntariamente, traçar uma fronteira entre si própria e uma cidade outra onde ela está inserida. A "cidade" em questão chamase Barra da Tijuca, um território enclave que responde por um éthos próprio, distinto daquele compartilhado do Túnel do Joá[1] para lá. Uma cidade-bairro que, registrada dentro de códigos do gênero terror adolescente, transforma-se ela mesma em uma personagem monstruosa, traiçoeira. Em um momento do filme, dois irmãos observam essa cidade/bairro encostados em um carro, nesse tempo suspenso da madrugada, e o que se escuta em cena é um programa de rádio, em que a voz da locutora fala:

Amanhece na Barra da Tijuca. E chega ao fim mais uma edição de nosso programa. São tempos de medo, de terror, de pesadelo. É preciso tomar cuidado, andar em grupos, evitar sair à noite. E lembrem-se: as faces mais doces podem esconder um assassino. Como disse o famoso serial killer Ted Bundy: 'nós somos seus amigos, nós somos seus vizinhos, nós estamos em toda parte’. Bom dia e até a próxima madrugada.

É nesse ambiente de "medo, terror, pesadelo" em que um outro assassino serial mata jovens mulheres - e, a determinada altura do filme, também jovens rapazes - nessa parte da cidade onde todos os espaços, sejam eles terrenos baldios ou edifícios de luxo de frente para terrenos baldios, parecem vazios, como um deserto projetado pelos melhores escritórios de arquitetura sediados em Miami - leia-se, sediados nos terrenos de uma imaginação de "futuro" fundada por uma elite branca. O filme está a todo momento usando de uma série de planos abertos para tentar capturar esse esvaziamento simultaneamente territorial e psicológico de uma região que foi pensada para representar esse "futuro" e que, no entanto, pela evidência visível de seus tratores estacionados e pelos guindastes imóveis - e é importante observar que essas máquinas da construção civil são filmadas aqui somente nesse estado de ora imobilidade, ora lentidão mais se assemelha a uma fantasmagoria de sua própria ambição. 


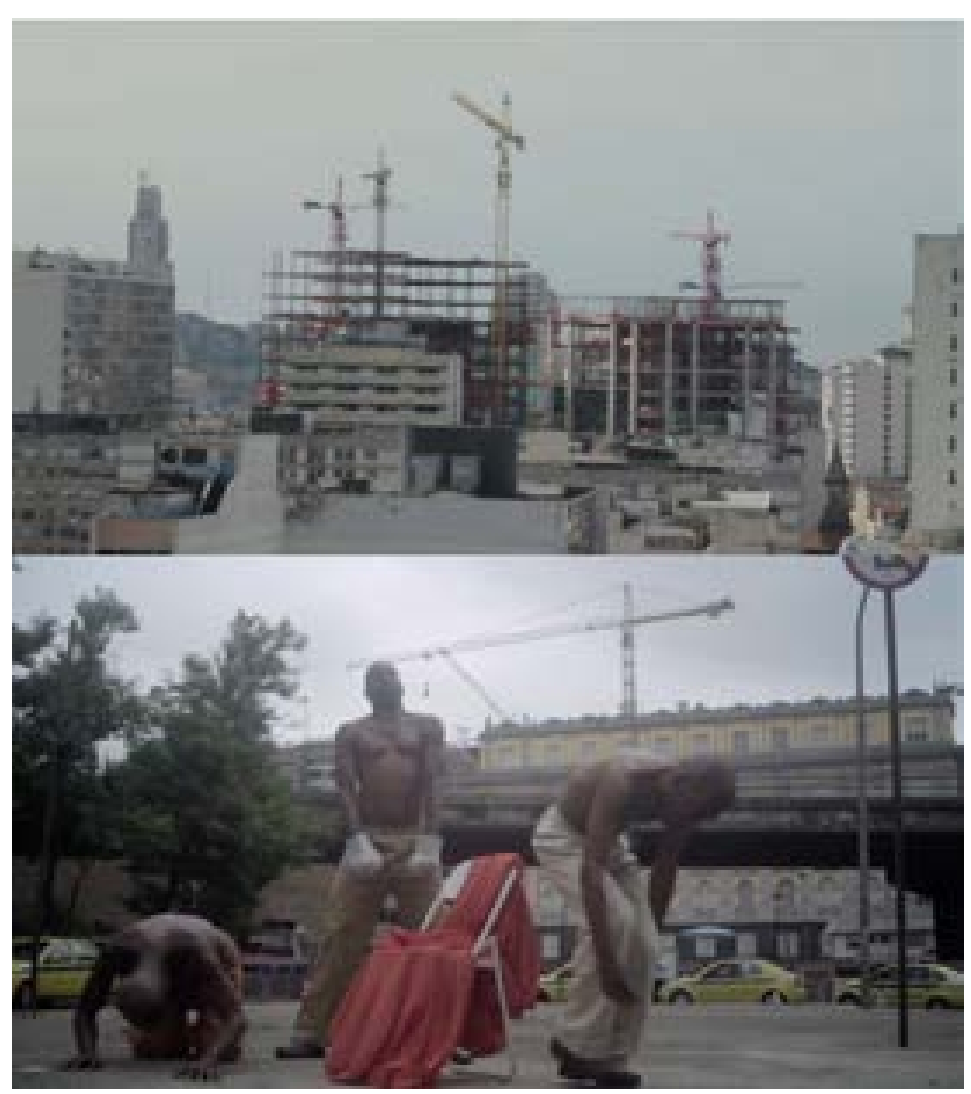

FIGURA 5: Print de tela

"O homem está na cidade, assim como a cidade está no homem". São com essas palavras, ditas numa narração em off pelo coreógrafo Gatto Larsen, que Esse amor que nos consome (2012), de Allan Ribeiro, coloca em colisão essas duas imagens (Fig. 5): a primeira, o plano aberto de uma cidade e seus gigantes equipamentos de construção. Logo depois, surge um grupo de três homens, todos negros, emulando em seus corpos a coreografia automatizada e robótica dessa cidade e das máquinas que fundam seus edifícios no chão. Ao centro do quadro, um desses homens vira um corpo-britadeira. Do lado direto da tela, um outro dá voltas em torno de algum eixo invisível que o parece puxar sempre para o mesmo lugar. No canto esquerdo, o terceiro sujeito está ajoelhado criando movimentos com os braços que podem tanto indicar gestos de reverência como tentativas frustradas de alguém que não consegue se erguer. A dança lateja transe. A música que faz surgir esse transe é das máquinas de construção. "Os dias se movem sem sair do lugar", Gatto Larsen havia dito pouco antes em seu ensaio sobre a cidade. Os três homens que têm como cenário de fundo carros, viaduto, uma construção que se assemelha a uma fábrica e um gigante guindaste se movem igualmente sem conseguir sair do lugar. Uma cidade dá voltas em torno de si mesma e todo movimento se torna, na verdade, um transe coletivo da 
imobilidade e do autocentramento. Um transe que, não obstante, produz um pensamento sobre a condição urbana. Um transe de saberes ainda não domesticados pela palavra.

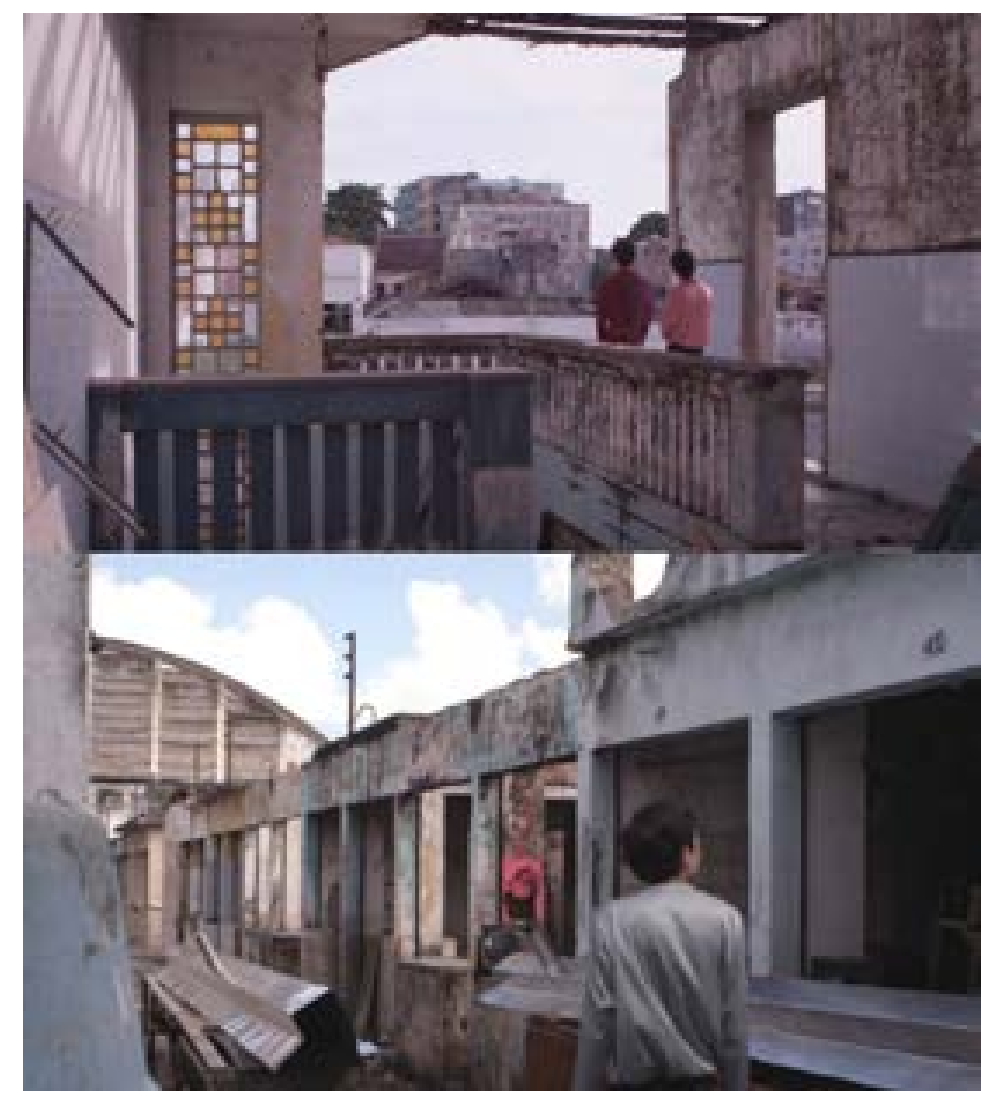

FIGURA 6: Print de tela

A cidade pela qual se anda em A Seita (2015), de André Antônio, foi, de fato, abandonada por boa parte da humanidade, que decidiu colonizar outros territórios, no caso "colônias espaciais", onde as pessoas não mais dormem e, portanto, não mais sonham. O Recife de 2040, onde e quando o filme se passa (Fig. 6), é dessa forma uma cidade que, embora esteja largada às ruínas e às poucas pessoas que nela sobraram, ainda consegue criar núcleos de resistência onde é possível dormir e sonhar, onde é possível ser inútil. Mas a inutilidade e o abraço à indiferença não parte aqui de um pensamento previamente combativo. Caminhar desinteressadamente por uma cidade de construções abandonadas é antes um gesto que se funda no tédio e é por dentro desse tédio, tão presente na pele do protagonista e de seus amantes, que é possível vislumbrar um tempo outro que não mais atende ao tempo funcional das "colônias". Poder sonhar é, sobretudo, poder pertencer a uma outra estrutura de tempo, uma em que todas as convenções de causalidade e linearidade evaporam. A contemplação dos espaços vazios 
enquanto ação diletante é um despropósito e isso é um fim em si mesmo. Leia-se: as ruínas da cidade não mais funcionam para um propósito de cidade da mesma forma que os corpos queers e dândis igualmente nunca funcionaram a um propósito de "progresso". O dandismo é um elemento importante para atravessar os modos de pensamento fílmico elaborados quando se colocam esses sujeitos em sobreposição à cidade. O fato, por exemplo, de que os corpos são sempre filmados de longe nos momentos em que observam o entorno de paredes sujas, azulejos quebrados e caminhos de cupins, é uma adesão formal ao próprio éthos distanciado e indiferente do dandismo, posto que este seria:

\footnotetext{
Um modo de se relacionar com o mundo que, por um lado, privilegia a doçura agradável do esteticismo, da beleza, da elegância, da delicadeza, do pitoresco ou pictórico, isto é, uma ordem e, por outro lado, paradoxalmente, pondo em xeque essa "ordem", como que a esvaziando, ao privilegiar a superficialidade, a frivolidade, a fragilidade, o artifício, o lúdico, a ironia ou wit, a indiferença ou a frieza (BARBOSA; LOPES; NEVES; DUARTE FILHO, 2019, p. 69).
}

Em uma das imagens, o protagonista (Pedro Neves) que observa a cidade-ruína de dentro de uma escola abandonada tenta dar conta dos afetos que o preenchem enquanto caminha por esse espaço: "não é nostalgia, é outra coisa, como se meu corpo ainda conhecesse esse lugar". Ele pode tanto estar se referindo ao fato de ter estudado também nessa escola, como também, numa perspectiva mais subjetiva, ter profunda aderência psicológica a esse espaço em função de uma irmandade entre corpos - ele e as construções desabitadas - que não "servem".

As questões temporais que se expandem a partir das sequências em questão são fundamentais para observar o que pode ser inferido sobre o cinema brasileiro dos anos 2010 quando ele manifesta, em várias sequências (as escolhidas aqui são apenas algumas delas) esse sintomático afeto da derrelição em planos abertos que colocam um certo projeto de cidade em questão. É imperioso então refletir sobre os regimes de temporalidade que atravessam especificamente essas sequências fílmicas. São tempos lineares? Cíclicos? Que relação as durações estabelecidas por essas imagens criam com os espaços que elas ocupam?

\section{OS TEMPOS CÍCLICOS}

Em que espaço de tempo é possível localizar o abandono quando este parece ser um projeto ainda em construção? Por que as sequências que se encontram neste artigo carregam dentro de suas composições um tempo que parece em vários momentos ser um "agora" que 
simultaneamente já aconteceu e ainda não chegou? Essas perguntas me movem ao desafio de indagar a própria noção de tempo com a qual a epistemologia ocidental nos habituou a ler o mundo. Por um lado, é inegável que essa mesma epistemologia abre brechas - e apresenta rasgos - fundamentais para o deslocamento do tempo e, particularmente da história enquanto linearidade em inequívoca caminhada rumo a um futuro "melhor". A se contar todas as vezes que essa noção de história foi contestada seja pela crítica à linearidade a partir da ideia do "eterno retorno" em Nietzsche, pela própria "ciência da cultura" (Kulturwissenschaft) e possibilidade de "sobrevivências" (Nachleben) em Aby Warburg e, claro, pelo "anjo da história" benjaminiano que, em lugar de ver "uma cadeia de acontecimentos, vê uma catástrofe única, que acumula incansavelmente ruína sobre ruína e as dispersa sobre nossos pés" (BENJAMIN, 1987, p. 226).

Os dois instrumentos teóricos que serão aqui dispostos para pensar as sequências em questão são a noção de "tempo espiralar" desenvolvida por Leda Maria Martins e as premissas do "tempo Exu" esmiuçadas por Muniz Sodré no livro em que ele se debruça sobre o pensamento Nagô.

O tempo em "espiral" que cria o movimento cíclico de constante encontro entre esse passado diante e o futuro detrás está também nas bases de uma noção filosófica-conceitual de matriz africana de "tempo espiralar", a qual Leda Maria Martins acionará para falar de performances ritualísticas do Congado, sistema religioso afro-brasileiro fundado nas "encruzilhadas" entre religiões de matriz africana e europeia. É, portanto, a partir do corpo e dos movimentos que ele escreve dentro do ritual, que se estabelece um registro de temporalidade desviante de uma lógica de sequencialidade linear. Martins descreve o mito fundador do Congado, que é o aparecimento de Nossa Senhora do Rosário no mar durante o período de escravidão no Brasil e sua busca primeiro por um grupo de homens escravizados do Congo e posteriormente pelo grupo dos Candombes. Ambos tentaram cativar a santa a sair do mar e chamá-la para terra a partir de cânticos, batidas sincopadas e danças. Com o grupo do Congo ela se ergueu das águas, com o de Candombe, ela acompanhou as pessoas até a terra. As celebrações do Congado recriam esse mito fundador a partir de rituais intricados e complexos que, dependendo de onde é performado, assume características particulares. Mas alguns elementos centrais são comuns a todo Congado. Martins frisa que nessas dramatizações há três enunciados fundamentais:

1) A descrição de uma situação de repressão vivenciada pelo negro escravo; 2) a reversão simbólica dessa situação com a retirada da santa das águas, sendo o canto e dança regidos pelos tambores; 3) instituição de uma hierarquia e de um outro poder, o africano, fundados pelo arcabouço mítico e místico (MARTINS, 2002, p. 80).

Nesse movimento de reversões simbólicas e a instituição, via ritual, de outra ordem de poder, Martins afirma que o texto mítico católico é rasurado e sobre ele se cria uma outra escritura em que Nossa Senhora do Rosário passa a evocar também "mães ctônicas africanas". 
A estrutura palimpsestica e fabular dessas encenações reverte, portanto, processos de dor em processos de libertação e "insemina o tecido religioso católico com a telúrica teologia africana" (MARTINS, 2002, p. 83).

Essas reversões e deslocamentos, no entanto, só são possíveis porque há dentro das performances do Congado gestos mobilizados pelas chamadas guardas que atualizam uma concepção elementar dentro da epistemologia africana que é o da ancestralidade. Fala-se de uma cosmovisão em que a reverência aos ancestrais não se reduz a uma reverência ao passado, mas sim às possibilidades de vida, incluindo nela aquilo que seria entendido como futuros possíveis e desejáveis. Pois que a ideia de ancestralidade implica necessariamente em circuitos que fazem cruzar o mundo dos vivos, dos mortos, do material e do divino, do individual e do coletivo. A convocação dessa ancestralidade dentro do ritual se dá a partir de corpos, muitas vezes ornados de objetos/instrumentos musicais que emitem sons, em cânticos e danças que, ao mesmo tempo que reverenciam os antepassados, criam "seus próprios tons e pegadas" como que afirmando algo sempre novo mesmo em danças que se repetem ritual após ritual. É sobre esse movimento dos corpos que Martins se debruça para criar a imagem de um tempo que condensa no presente da ação performática a simultaneidade do passado e do futuro:

O corpo em performance, nos Congados, é o lugar do curviliniamente ainda é e já é, do que pôde e pode vir a ser, por sê-lo na simultaneidade da presença e da pertença. $O$ evento encenado no e pelo corpo inscreve o sujeito e a cultura numa espacialidade descontínua que engendra uma temporalidade cumulativa e acumulativa, compacta e fluida (MARTINS, 2002, p. 86-87, grifos da autora).

O corpo que performa dentro dessa convocação de ancestralidades produz: 1) o que Pierre Nora chama de ambientes de memória (milieux de mémoire), que são diferentes do que lugares de memória (lieux de mémoire), ou seja, dos espaços institucionais que organizam, catalogam e oficializam a memória, tais como museus, bibliotecas e monumentos públicos e 2) o que a própria Leda Maria Martins chama de oralitura, uma escrita do corpo criada a partir de coreografias côncavas e convexas que abrem o tempo do acontecimento da performance em uma espiral onde repetições são sempre originais.

O repertório da ancestralidade está também atravessado na complexa concepção de tempo no pensamento nagô a partir da figura de Exu. É com um aforisma popular que Muniz Sodré começa seu caminho pela compreensão filosófica do conceito: "Exu matou um pássaro ontem com a pedra que atirou hoje". Para que se possa chegar à operação de tempo dada pelo aforisma é preciso, primeiro, entender o lugar de Exu dentro das estruturas ontológicas e epistemológicas iorubá-nagô. A começar pelo fato de que Exu é uma força constituinte da vida. Pelo fato de que ele é o princípio da existência, não é possível haver vida sem Exu, e todos os seres vivos, da fauna e da flora, têm o seu próprio Exu. 
Nesse sentido, a configuração do "eu", dentro do pensamento Nagô, "não figura como fundamento da subjetividade e sim como uma unidade diferencial e pré-individual $(E x u)$ investida de uma potência (axé) cuja intensidade se desdobra no desenvolvimento ontogenético do indivíduo" (SODRÉ, 2017, n.p, grifos do autor). Em outras palavras, não existe um tornar-se sujeito a partir de um processo isolado, atomizado, distante do entorno. Não há individualização, mas sim algo mais próximo àquilo que Jung chamaria de individuação (o indivíduo em ação), em que o "eu" só conquista um equilíbrio a partir de um constante e incessante movimento entre o cósmico e o físico. No caso de Exu, é ele o responsável por ir buscar no espaço suprassensível (orun) a matéria originária da vida (ipori, a placenta) e levá-la até o espaço natural (aiê). Essa comunicação que se estabelece entre o cósmico e o físico, entre o orun e o aiê, entre a água (o sêmen) e a terra (o útero) é dada por Exu.

Para além da dimensão comunicativa de Exu, existe uma importante dimensão erótica que, igualmente, abrirá chaves de compreensão de como a ideia de tempo se organiza nessa cosmologia. Exu compreende o erótico como uma força afirmativa da vida e, como tal, uma energia diretamente ligada ao sagrado. Nesse sentido, se distingue bastante, por exemplo, de uma moral sexual cristã, que faz uma associação muito imediata entre o "pecado original" e o sexo. A "arkhé africana reserva ao erótico uma dimensão de ambivalências - profundidade e mistério - mais ampla do que a implicada na simples reprodução sexual " (SODRÉ, 2017, n.p).

Eis um ponto fundamental para a compreensão do tempo dentro desse princípio vital que é Exu. O erótico quando lido apenas como uma ação com vistas à reprodução dos seres e, particularmente, do ser humano, obedece a uma estrutura cronológica do pensamento pois pressupõe a atividade sexual como uma linha de continuidade das espécies. Para o pensamento nagô, o sexo é antes um processo de comunicação entre ancestralidade e descendência, entre o dentro e o fora. O sexo é uma insubordinação à materialidade de um corpo mortal, uma vez que o gozo cria uma comunicação direta com o mítico e o sagrado e esse elo é capaz de abrir o tempo da vida, não mais como continuidade, mas como acontecimento.

É pela noção de acontecimento que Sodré introduz as diferenças mais centrais entre o tempo Exu e o tempo que se temporaliza como medida. O acontecimento, neste caso, não pode ser lido como um evento, mas como uma experiência singular e única, que rompe o fluxo das coisas porque introduz algo radicalmente novo. Não se trata, no entanto, de um ponto "original" que se possa datar, mas de uma potência de começo porque estabelece um princípio (princípio enquanto fundamento) tanto do ponto de partida quanto do ponto de chegada. "Em outras palavras, o acontecimento é o começo de algo que vem, de um a vir, mas um começo que se dá no meio" (SODRÉ, 2017, n.p).

Exu, que é simultaneamente a representação do ancestral e do descendente, condensa assim a imagem - e talvez essa seja a forma mais fácil de compreender o tempo Exu - de um 
"agora" que surge a partir da coexistência entre o nascente e o poente, visto que esses dois fenômenos, quando observados de uma distância da Terra, acontecem sempre exatamente no mesmo momento. É o agora, portanto, que funda todos os tempos, o começo e o fim. E porque é esse agora que possibilita o desdobramento para frente e para trás do tempo, que se pode entender "Exu matou um pássaro ontem com a pedra que atirou hoje". Pois que "hoje", em Exu, é o acontecimento-princípio que coexiste, tal como o nascente e o poente, com o passado.

Existe aí uma ruptura drástica com a ideia de tempo linear e, mais substancialmente, com um princípio de irreversibilidade de todas as coisas e, por consequência, de sistemas de poder que se alimentam não apenas de um direcionamento para "rumo ao futuro", mas mais particularmente na noção de que não é possível reverter o tempo, pois isso faria extinguir o medo e, portanto, a possibilidade de fundar regimes de poder com base na administração desse medo.

Diante dessas perspectivas de tempo, volto à pergunta: em que espaço de tempo é possível localizar o abandono quando este parece ser um projeto ainda em construção? Não foram poucos os filmes, entre ficções, documentários e as várias narrativas híbridas, que durante os anos 2010 se debruçaram sobre os pactos existenciais de se viver em grandes centros urbanos e todo malestar gerado por projetos desenvolvimentistas impostos sobre as cidades. Mas em alguns títulos em especial, é possível perceber esse cinema apontando a câmera para um acúmulo de ruínas a "catástrofe única" de Benjamin - que, mais do que imaginar ambientes distópicos do presente e do futuro, projeta na verdade imagens potencialmente arqueológicas. O que se enquadra só virá a acontecer porque, de fato, já aconteceu.

\section{O TEMPO DAS RUÍNAS FUTURISTAS}

Vejamos novamente os prédios corroídos de $A$ Seita. O filme traz em seus créditos de abertura enquadramentos fixos com várias imagens de um Recife desertificado no imaginado ano de 2040, com ruas e prédios vazios. A projeção distópica é uma presença imediata do filme. Mas porque esse é um trabalho que joga o jogo da superficialidade, essa distopia se torna, no último bloco do longa, disfarce para um outro tipo de espaço com o qual o filme compactua mais firmemente, um espaço que é literalmente sonhado em nome de uma experiência coletiva. "A Seita" em questão é um grupo de pessoas que se reúne num ambiente dedicado à contemplação esteta, ao "belo". São elas quem planejam eliminar o efeito da vacina dada à população para que esta não possa mais nem dormir, nem sonhar. Na sensibilidade dândi, a capacidade de se colocar 
dentro do tempo suspenso do sonho é uma estratégia de enfretamento a um sistema que impõe não somente uma relação utilitarista com o mundo, mas sobretudo uma recusa a funcionar dentro de uma estrutura temporal guiada por uma ideia de evolução.

Quando um dos personagens do filme, dentro de mais um dos espaços em ruínas que são colecionados na narrativa, diz: "não é nostalgia, é outra coisa, como se meu corpo ainda conhecesse esse lugar", é possível pensar a performance do corpo dândi simultaneamente apático e sonhador como um ambiente de memória (milieux de mémoire). Um corpo que nos deixa ver o tempo em um ciclo de apatia e delírio, que é a memória que se vive nesse espaço. A própria estrutura do filme em revelar essas paisagens de ruínas como repetições que vão aparecendo e reaparecendo na narrativa indica que esses corpos e a maneira como eles posam para a câmera estão ali como uma reencenação dessa condição onírica que fissuram uma temporalidade homogênea. Ainda que $A$ Seita passe longe de qualquer debate sobre a estrutura espiralar de ancestralidade convocada, por exemplo, pelos rituais do Congado, é importante observar como ele também se utiliza dos corpos em cena como manifestações materiais do tempo enquanto uma performance contemplativa em eterno retorno.

A apatia é também uma presença central em Mate-me por favor, cuja sequência final captura mais um terreno baldio diante de edifícios ao fundo e onde se vê, aos poucos, figurações zumbis (figurações ruínas) surgirem em cena, adolescentes mortos caminhando rumo ao nada que se coloca diante deles. As retroescavadeiras prostradas sobre a avenida da Barra da Tijuca não são, nesse sentido, objetos que catalisam a ideia de desenvolvimento, mas sim máquinas que quando simulam erguer o futuro, escavam ossos de uma classe média que devora a si mesma. Assim como A Seita, o filme de Anita Rocha da Silveira não apenas flerta com uma estética camp, do exagero e do artifício, mas cria um ambiente que é, tal como na sequência em que se escuta uma locutora de rádio falar de "tempos de medo, de terror, de pesadelo", onírico, não-real. Mas, ao contrário do que acontece em $A$ Seita, o sonho não é mais uma estratégia de recusa a um sistema, o sonho é um pesadelo do qual não se consegue escapar. Em função disso, os códigos do gênero terror são acionados em vários momentos. O tempo do filme, não à toa, é ditado por assassinatos em série de adolescentes, ou seja, por mortes que surgem como acontecimentos repetidos e, no entanto, originais.

No processo de tentar capturar outras estruturas de tempo, esse cinema cria também corpos que, tais como aqueles que se movem em coreografias côncavas e convexas na sequência-chave de Esse amor que nos consome, produzem oralituras sobre a experiência urbana (que bibliotecas saberão guardar esses escritos?) e mimetizam esse tempo cíclico que não para de se repetir, ainda que a cada repetição, um acontecimento novo exploda o tempo para todos os lados. $O$ filme de Allan Ribeiro, aliás, faz dentro dele mesmo um exercício de transformar a cidade em um 
espaço de encruzilhadas, onde o externo e o interno se encontram, se atraem e se repelem a partir justamente das performances de dança. A montagem dentro do filme que sai da paisagem fria de um Rio de Janeiro tomado por máquinas de construção e prédios gigantes para a imagem de dançarinos numa coreografia de transe que emula os movimentos dessa mesma cidade pode ser lida como uma montagem-encruzilhada, no sentido específico de que ela cria um ponto de encontro e dispersão entre o ser a cidade e o ser na cidade. Usando esse conceito como uma chave teórica para observar os ritos do Congado, Martins escreve:

Na concepção filosófica nagô/iorubá, assim como na cosmovisão de mundo das
cultura banto, a encruzilhada é o lugar sagrado das intermediações entre sistemas
e instâncias de conhecimentos diversos, sendo frequentemente traduzida por um
cosmograma que aponta para o movimento circular do cosmos e do espírito
humano que gravitam na circunferência de suas linhas de interseção. (...) Da
esfera do rito e, portanto, da performance, a encruzilhada é um lugar radial
de centramento e descentramento, interseções e desvios, texto e traduções,
confluências e alterações, influências e divergências, fusões e rupturas,
multiplicidade e convergência, unidade e pluralidade, origem e disseminação
(MARTINS, 2002, p. 73).

A encruzilhada é, portanto, um operador capaz de simultaneamente articular os cruzamentos e irradiações entre espaços ("centramento e descentramento"), como os cruzamentos e a irradiações entre tempos ("origem e disseminação"). O tempo de Branco sai preto fica, por exemplo, encontra-se na encruzilhada da história e, não à toa, termina explodindo para todos os lados em seu desfecho. Fala-se de um filme que acontece em um tempo que não conseguimos localizar com precisão e se articula com ideias de passado e futuro estranhamente situadas em um infinito aqui-agora. Na cartela que surge antes da primeira imagem do filme, lê-se: "Antiga Ceilândia, Distrito Federal", de onde se deduz em um primeiro momento que o filme se desenrola no passado. O passado, no entanto, é o único projeto de futuro para Ceilândia, enquanto o futuro parece já ter chegado.

O espaço vazio que o agente Dimas Cravalança percorre até chegar à sua máquina do tempo é também o espaço de apagamentos históricos que atuam na supressão de qualquer horizonte possível. Portanto, Dimas não é apenas um personagem que sai, na cena em específico, de um ponto A em direção a um ponto B. Ele é uma força que, ao cruzar a tela, imprime sobre essa imagem uma rasura, uma falha no sistema. Sua existência é um bug nos modos de organização do mundo tal qual o conhecemos, cuja lógica figurativa comporta a presença de prédios gigantes, mas não comporta esse corpo estranho. Ele é a pregnância do desvio que se encontra presente também, ainda que não na mesma intensidade, nos corpos dândis que se recusam a serem funcionais em $A$ Seita, nos bailarinos que rompem com a normalidade da cidade ao criarem uma performance espiralar sobre o automatismo da mesma cidade. São pessoas que estão para o regime espaço-temporal dos centros urbanos tal como peças defeituosas estão para máquinas que todos se recusam a desligar. 
Há particularmente em BSPF uma outra chave de leitura das imagens que se agrupam neste artigo. Porque se falamos de conceitos de espaço e de tempo que latejam entre as sequências, estamos lidando não apenas com registros de memória inscritas nos corpos e as pulsões de ação, poesia ou dormência que se desdobram dessas memórias, mas no caso da cinematografia de Adirley Queirós, lidando também a perspectiva de uma reversibilidade da história e, portanto, tal como no tempo Exu, de uma reversibilidade do tempo. Isso só é possível pelo gesto de reivindicar aquilo que, em BSPF, Cláudia Mesquita dá o nome de "contra-fiç̧ão" (MESQUITA, 2015) visto que esta aciona ferramentas da ficção científica para levar um viajante do tempo a um tempo que não se consegue situar, porque a cidade periférica visitada por esse sujeito é uma que simultaneamente já existiu, ainda existe e permanece existindo no futuro.

\section{NOTAS CONCLUSIVAS: O TEMPO E OS TRAUMAS}

A história relida pelo ponto de vista do trauma mobiliza a reversibilidade do tempo porque é o trauma que aciona o gatilho para a imaginação. "O foco no trauma é legítimo em nações ou grupos de pessoas que estão tentando criar ajustes de contas com a história de violências sofridas ou violências perpetradas" (HUYSSEN, 2003, p. 9, tradução minha). O argumento de Huyssen é, na verdade, lido em seu texto como uma exceção à regra. Ou seja, a regra deveria ser entender o trauma não como elemento central da análise histórica, mas como uma das camadas que precisam ser articuladas em um panorama internacional. Colocar o elemento traumático como eixo central da observação só valeria em casos de lugares onde as pessoas estariam tentando lidar com o passado e o presente de violências. A pergunta é inevitável: mas que lugar no planeta não se encaixa nesse perfil? Não seria o problema mesmo da história ocidental criar fronteiras bem definidas entre o que é, ou não, um espaço de violência?

No mesmo texto, Huyssen afirma que a "crise da história" no novo milênio se dá não somente porque a versão iluminista de que essa disciplina serviria para evitar erros do futuro teria se provado falha (e o exemplo usado para provar esse equívoco é sempre o do Holocausto, nunca do projeto colonial), mas porque estaríamos vivendo um momento de compressão cada vez maior do tempo-espaço. Há, segundo ele, uma "devagar, mas palpável transformação na temporalidade de nossas vidas, provocada pela complexa interseção de mudanças tecnológicas, mídia de massa e novos padrões de consumo, trabalho e mobilidade global" (HUYSSEN, 2003, p. 21, tradução minha) e isso estaria fraturando a noção de continuidade do tempo. 
Certamente, em um contexto global em que as discussões sobre memória e história participam de uma agenda que inclui ações nas instituições que representam o lieux de mémoire, as preocupações com essa quebra na noção de continuidade por uma compressão do tempoespaço são legítimas. No entanto, quando se observa algumas imagens mobilizadas por vários filmes brasileiros dos anos 2010, o referencial dessa específica "crise da história" parece ser insuficiente para dar conta do páthos ruína que pulsa nessas sequências justamente porque não consegue se articular com outras possibilidades de regimes temporais que não seja exatamente esse da continuidade, da sequencialidade.

Sem o conceito de tempo cíclico ou espiralar, se torna difícil entender como esses filmes reforçam um estar no mundo e, particularmente, nas grandes cidades, como uma experiência de viver numa narrativa que coloca as pessoas em constante estado de déjà-vu, observando paisagens de ruínas que anunciam aquilo que já aconteceu. Os dândis de $A$ Seita, os bailarinos de Esse amor que nos consome, os adolescentes de Mate-me por favor e o viajante do tempo de Branco sai preto fica estão todos habitando um espaço onde o tempo dá voltas sobre si mesmo e onde a ideia de "futuro" é instrumentalizada para camuflar traumas que se repetem sem cessar.

A escolha das sequências selecionadas desses quatro filmes se dá a partir de instantes dentro das narrativas em que as imagens abrem o tempo para frente e para trás, quando a câmera registra a materialidade desse estado de suspensão em que a própria constituição retilínea da linha passado presente futuro é questionada, posto que todas essas narrativas estão diretamente se endereçando a um debate sobre a falência de projetos de cidade que apostaram e apostam em modelos de especulação imobiliária, gentrificação e projeções de futuro que apenas repetem estruturas coloniais.

Mas, sobretudo, é com o conceito de tempo cíclico ou espiralar que fica possível perceber como o futuro estacionado, imobilizado e amputado de Branco sai preto fica não cansa de se atualizar. Do mesmo modo que a pedra que Exu atirou hoje para matar um pássaro ontem é "a metonímia do acontecimento", como frisa Sodré, Dimas é a metonímia da própria história do Brasil, um corpo negro que, em sua viagem no tempo, permanece para sempre preso em um agora que se suspende no momento em que o disparo da sirene é acionado. Dentro de sua máquina do tempo, Dimas é assombrado pelos eventos daquele 5 de março de 1986, quando o baile black que acontecia no Quarentão, em Ceilândia, foi invadido pela polícia, ferindo e mutilando vários homens negros como ele. Dentro dessa mesma máquina do tempo, é possível ver Dimas parar diante das imagens de seis policiais militares que armaram uma emboscada em um baile funk na periferia da cidade de São Paulo, matando com isso seis jovens negros, que tinham entre 14 e 23 anos, na madrugada do dia 2 de dezembro de 2019. O dia 5 de março de 1986 e o dia 2 de dezembro de 2019 são o mesmo dia de vários outros dias em que o mesmo gesto acontece e, no entanto, eles se tornam acontecimentos porque são radicalmente novos nas rupturas que provocam. 


\section{REFERÊNCIAS}

BARBOSA, André Antônio; LOPES, Denilson; NEVES, Pedro Pinheiro; DUARTE FILHO, Ricardo. Inúteis, frívolos e distantes: à procura dos dândis. Rio de Janeiro: Mauad X, 2019.

BENJAMIN, Walter. Magia e técnica, arte e política: ensaios sobre literatura e história da cultura, trad. de Sergio Paulo Rouanet. São Paulo: Brasiliense, 1987.

HUYSSEN, Andreas. Present pasts: urban palimpsests and the politics of memory. Stanford: Stanford University Press, 2003.

MARTINS, Leda Maria. Performances do tempo espiralar. In: RAVETTI, Graciela; ARBEX, Márcia (org.) Performance, exílio, fronteiras: errâncias territoriais e textuais. Belo Horizonte: Departamento de Letras Românicas, Faculdade de Letras, Poslit, 2002.

MESQUITA, Claudia. Memória contra utopia: Branco sai, preto fica (Adirley Queirós, 2014). XXVI Encontro da Compós- GT Fotografia, Cinema e Vídeo, São Paulo, 2015. Disponível em: <http://www.compos.org.br/ biblioteca/compos-2015-1a0eeebb-2a95-4e2a-8c4b-c0f6999c1d34_2839.pdf>.

MESQUITA, Claudia. O avesso do futuro: memória, distopia e condição precária em Branco sai, preto fica. In: ALMEIDA, Rodrigo; MOURA, Luís Fernando (org.). Brasil distópico. Rio de Janeiro: Caixa Cultural, 2017.

SODRÉ, Muniz. Pensar Nagô. Petrópolis: Vozes, 2017. E-book.

[1] Principal túnel que liga a Zona Sul da cidade do Rio de Janeiro ao bairro da Barra da Tijuca. 